\title{
Eulogy for Professor Romuald Kreczko
}

On September $22^{\text {nd }} 2020$, we received a sad news that outstanding Polish orthopaedist passed away.

Professor Kreczko was born in 1928 in the village of Osse near the town of Łapy the latter being at that time, as Professor often recalled, a seat of the largest Polish railway carriage factory. Professor's father was an engineer at that plant.

In 1954, Professor finished his medical studies at the Medical Faculty of the Medical Academy in Łódź and was directed to work in a place far away: Żory near Żagań. Earning a scholarship to specialize in orthopaedics and trauma surgery enabled his transfer in 1956 to the newly opened unit of the Silesian Medical Academy in Bytom

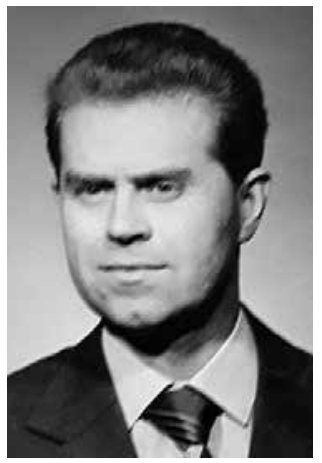
- The Department and Clinic of Orthopaedics. The chair of the newly opened Clinic was Prof. Marian Garlicki, with whom Romuald Kreczko - a young medical doctor, still at the beginning of his professional career was to work for many years to come. Next year Romuald Kreczko moved to Warsaw and was employed at the $2^{\text {nd }}$ Department of Orthopaedics and Trauma Surgery at the Central Clinical Hospital of the Warsaw Medical Academy. He specialized in orthopaedics and traumatology of the locomotor system and 1963 defended his doctoral dissertation. In 1966, together with Prof. Marian Garlicki, he moved to the Warsaw Orthopaedics Clinic, seated in Warsaw at Lindley Street, where he worked until 1987.

In 1972, he earned a habilitation degree defending post-doctoral dissertation entitled "The evaluation of McMurray and Pauwels osteotomy in the light of clinical and experimental research". In 1983, he received a full professor degree. Professor Kreczko used the experience earned while preparing his post-doctoral thesis to publish, together with Prof. Marian Garlicki, a first Polish monography on the orthopaedic problems of the hip joint - including its arthroplasty - the "Arthrosis deformans coxae". Since 1978, for a two-term period, he had been a vice-dean of the Medical Faculty of the Warsaw Medical Academy. He was very involved in numerous activities of his Clinic and of the Academy as a whole, conducting courses for students and medical doctors. For many years, he had been a consultant for the medical resort of Ciechocinek. In 1987, Professor Romuald Kreczko became a head of the Clinic of Rheumoortopaedics at the Institute of Rheumatology in Warsaw, where he worked until his retirement in 1998.

Throughout his career Professor Kreczko visited many international clinical centres, expanding his clinical and scientific experience. He most fondly recalled hist year-long stay in the United Kingdom in 1970s and the clinical knowledge gained there. He supervised 9 doctoral theses and was reviewer of 30 doctoral and 6 post-doctoral theses, as well as of 7 applications for a professor 's degree.

In his professional career he always put the patient's well-being first, always willing to help those in need. In his work he emphasized the role of an orthopaedist in fighting disabilities of the locomotor system. Diligent in his own work, he also helped his co-workers who could always count on his assistance and advise. But above all, he was a good and honest man.

For his professional achievements he was awarded the highest honour of the Polish Society of Orthopaedics and Traumatology (of which he was an honorary member) - the Professor Adam Gruca Medal.

He will be remembered by all of us as one of the most prominent Polish orthopaedists. 